\title{
Milling Damaged Starch (MDS) in wheat flour: Formation, Structure, Functionality and its Effects on Baking Quality: An Article
}

\author{
Abo-Dief, M. F. \\ Arabian Milling and Food Industries Company, Bourge El Arab, Alexandria, Egypt.
}

Received: 13 December, 2020

Revised: 26 December, 2020

Accepted: 30 December, 2020

\begin{abstract}
In this article, the Milling Damaged Starch (MDS) in discussed in terms of formation, structure. functionality and its effects on the quality of baking products. The MDS is different from native starch regarding granular structure, crystalinity and molecular degradation. Such a diversity is responsible for the different functionality of MDS. So ,gelatinization, pasting properties, in vitro enzymatic digestibility of wheat flour containing high level of MDS vary considerably as compared with their counter parts properties in wheat flour containing low MDS. This article discusses all the aforementioned information.
\end{abstract}

Keywords: Damaged starch, structure, gelatinization, functionality, baking quality.

\section{INTRODUCTION}

Due to forces (friction, shear, collision and impingement) applied on wheat kernels during milling , breaking of starch granules occurs, resulting in formation of Milling Damaged Starch (Suki et al., 2016, Zhang et al., 2019).

The MDS level in wheat flour affects considerably the baking quality of bread. Such an effect can be attributed to the elevation of both water absorption capacity (WAC) and rate of enzymatic hydrolysis in MDS as compared to the native starch. In other words, moderate MDS level could be improve dough quality, on contrary to high MDS level which leads to starch dough as found by Barrera et al., (2013) and Wang et al., (2017)

Recently, numerous researches have targeted at uncovering the diversity in structure, physicochemical and functionality of MDS (Hackenberg et al 2016, Ooms et al, 2018). Meanwhile, Wang \& Zheng (2020) published an extensive review on MDS in terms of generation, measurement, functionality along with its effect on starch-based food systems. The present article summarizes the effect of milling conditions on MDS and thereby its effect on the quality of baking products.

\section{Factors affecting formation of MDS}

Quality of wheat kernels, flour coarseness and milling conditions are the main three factors affecting formation of MDS. Harder wheat grains possess higher MDS than the soft ones. This can be attributed to the requirement of stronger milling force to destroy the tightly structure of starch grains belonging to harder grains. Consequently, the damaged severity increases (Makowska et al., 2014, Abo-Dief, 2020).

Wheat flour contains starch in a range of 78$82 \%$. The level of MDS depends on hardness of the kernel as well as grinding severity as reported by Scanlon et al., (1988). Obviously, more grinding energy is required for hard grains to mill endosperm into flour (Posner \& Hibbs, 2005, AboDief et al ., 2019)

It is noteworthy that MDS content affects the quality of flour. Wet gluten along with MDS play a pivotal role in determining dough and thereby bread quality. According to Wang \& Z Zheng (2020), higher level of MDS and lowest gluten content (by hard milling) causes a dilution of gluten network and consequently reduces its ability to holding more water. The wide variation in the amount of MDS in wheat flour can be attributed to the tempering conditions and process of reduction during milling. Notwithstanding, it was reported that the flour physical properties including colour, particle size and MDS are influenced by each of the following factors: wheat quality, milling system (Barak et al., 2014, Rahil et al., 2015, Sakhare et al., 2015).

Leon et al (2006) found that Properties of bread during storage is controlled by higher level 
of MDS. This effect is a result of lowering starchgelatinization enthalpy $(\Delta \mathrm{H})$ and higher melting enthalpy of amylase-lipid complex.

Compared to dry milling, wet milling could better ensure starch granular integrity as a result of absorption the heat generated through milling. Such an effect is due to the excessive water addition. Accordingly, hindering the temperature elevation and decline MDS (Almmad \& Rajab, 2018).

Abo Dief (2020) found that prolonging the period of tempering to $36 \mathrm{hr}$ at $12 \mathrm{C}^{\circ}$ resulted in a decline in the level of MDS for Australian and Russian wheat. This can be attributed to the lower tempering temperature which lower water penetration within the wheat grain and thereby required longer time until the endosperm becomes moist. So, the starch granules become more resistant to pressure and shear forces applied by milling rollers as a result of extending tempering period to $36 \mathrm{hr}$.

\section{Structure of MDS}

Granules of MDS are rough, distored and deformed. The greater MDS level is, the rougher and more irregular and distroed starch granule is (Barrera et al., 2013, Sakhare \& Inamdar, 2014, Wu et al., 2018).

Scanning electron microscopic (SEM) examination was used by Abo-Dief (2020) to illustrate the effect of tempering conditions (tempering and time) along with milling systems on the appearance and size of starch granules. The photographs showed that the hard milling gave more damaged starch, cracked flatted or less rouned for the flour of the two cultivars (Australian and Russian) than that of normal milling (Figure 1 and 2). Also, the tempering at $12 \mathrm{C}^{\circ}$ had generally some effects for different tempering times being less pronounced on the appearance of starch granules. Such $n$ effect can be explained on the basis that the amorphous amylose, like a flexible mechanical plasticizer, could absorb excessive shock and cushion the destruction of amylopectin crystalinity via external forces in starch granules, and thereby alleviating the particle size reduction (Liu et al., 2018).

\section{Functionality of MDS}

Generally, a decreasing of tendency in both gelatinization temperature and enthalpy $(\Delta \mathrm{H})$ could be traced as a results of high MDS level (Shi et al., 2016). This phenomenon can be attributed to the increased disorder in crystalinity structure of starch, which in turn reduces the energy required for gelatinization. Obviously, moisture content plays a pivotal role in gelatinization of MDS (Liu et al., 2018). The MDS often has lower viscosity, which results in fragile surface of broken MDS when they get swollen during gelatinization (Tan et al., 2015)

Regarding water hydration property of MDS, the higher the milling severity is $m$, the greater the MDS solubility is (Dhital et al., 2010 \& Liu et al., 2017). The point of interest is that the MDS has augmented rate of in vitro digestibility, on contrary to native starch. It was reported that higher MDS could be result in greater digestibility percentage.

\section{Effect of MDS on baking quality}

The MDS plays a key role in determining the quality of baking products. For instance, texture of these products is influenced by MDS (Liu et al., 2019)

Bread produced from flour has high MDS level gives loves of low specific volume (Hackenberg et al., 2016). Due to the high water capacity of MDS, enzymatic hydrolysis is reported in addition to lowering the formation of fermentable sugar and consequently dimishing the amount of gas generated during fermentation (Hackenberg et al., 2016). In other words, MDS may cause disruption of gluten network. Such an effect lead to poor ability of dough to hold gas. Moreover, it was found that MDS has effect on colour of the baked products and accordingly affects the appeal of consumers (Vouris et al., 2018).

Use of wheat flour containing high MDS was found to diminish the diameter of cookies. This can be explained based on the MDS which leads to stiff dough (Barak et al., 2014, Mancebo, et al., 2015)

In a conclusion, MDS plays a pivotal role in determining quality of wheat flour and subsequently the baking products made from it (Abo-Dief, 2020, Wang \& Zheng, 2020).

\section{REFERENCES}

Abo-Dief, M., Abo-Bakr, T., Youssef, M., \& Moustafa, A. 2019. Quality of wheat flour and pan bread as influenced by the tempering time and milling system. Cereal Chemistry, 96:429-438.

Abo-Dief, M.F. 2020. Modification of some technological conditions of wheat milling process to improve the quality and the functionality of flour. Phd. Thesis, University of Alexandria. 
Tempering at $32 \mathrm{C}^{\circ}$

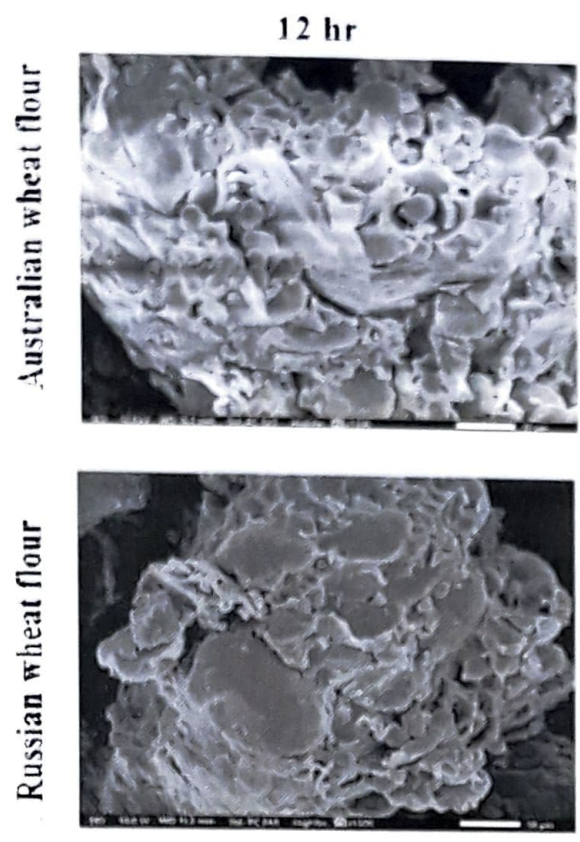

Tempering at $12 \mathrm{C}^{\circ}$
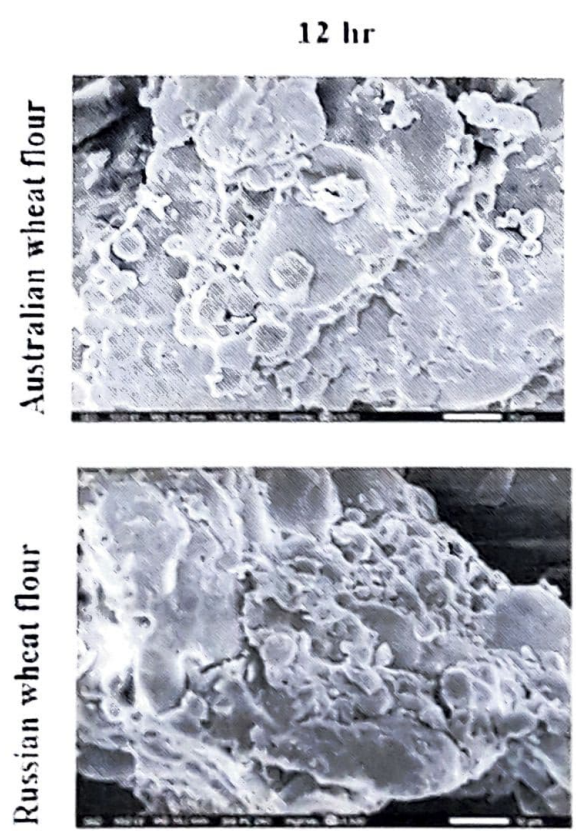

\section{Tempering time}
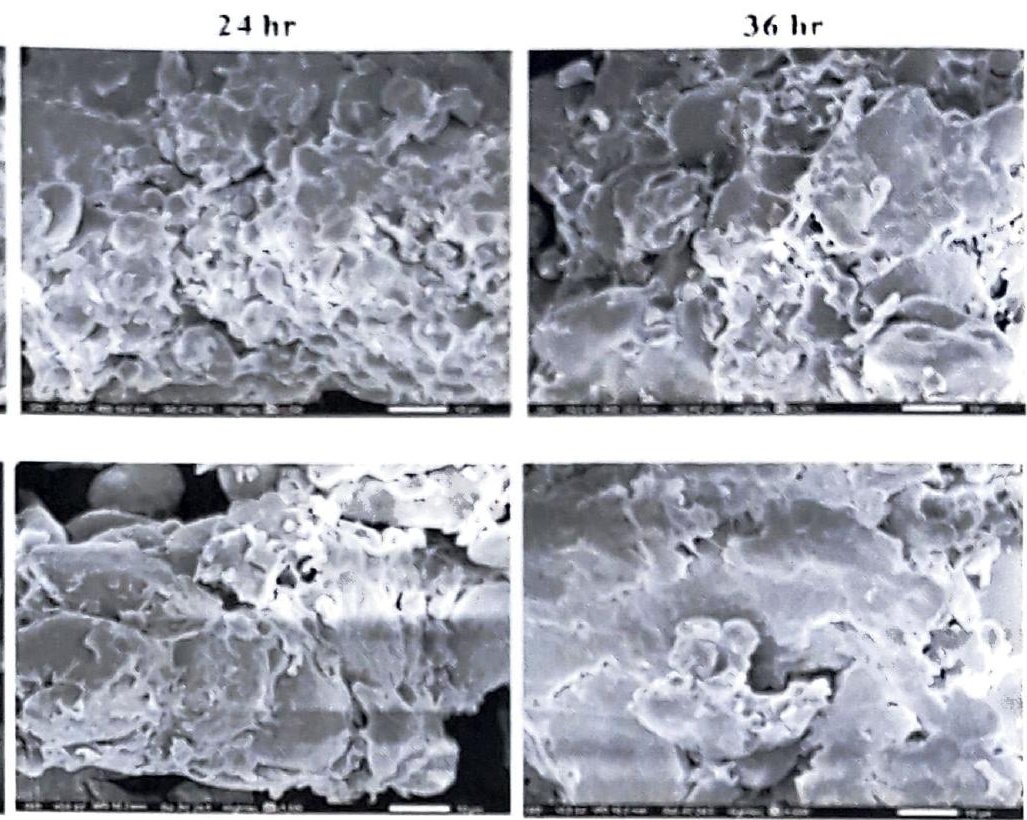

Tempering time

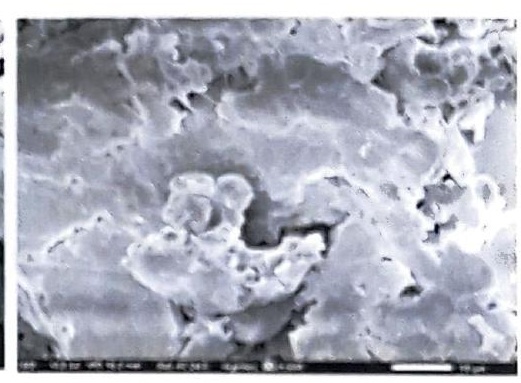

$2+h \mathrm{r}$
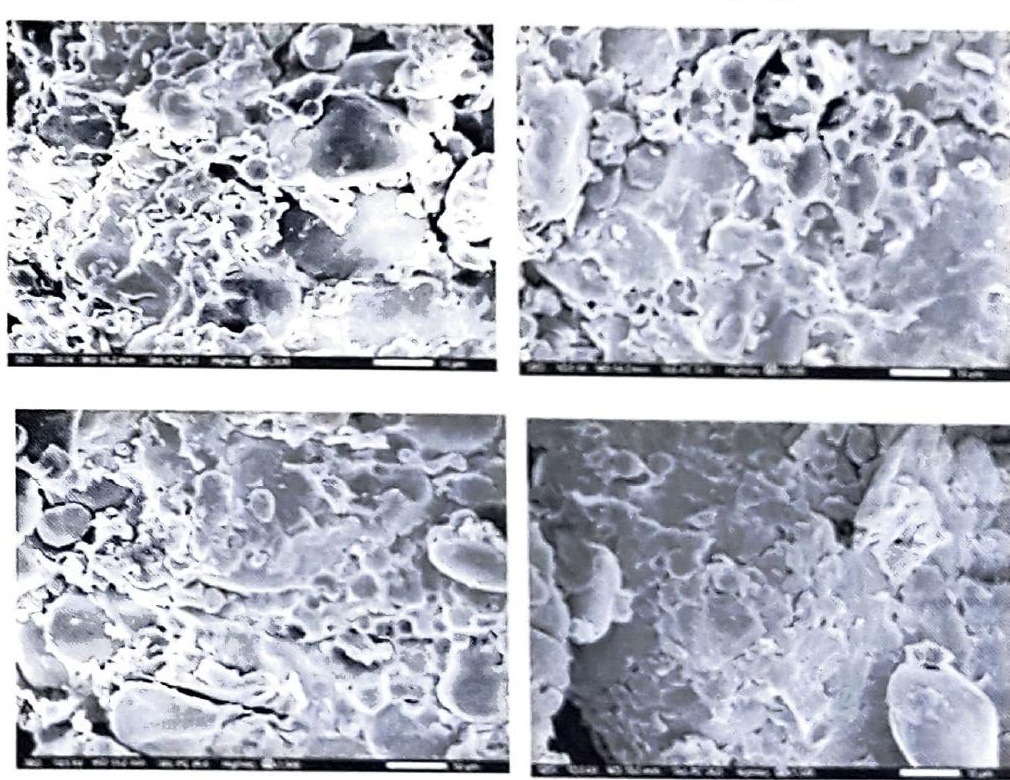

Fig. 1: Effect of tempering conditions and hard milling system on starch appearance for Australia and Russian wheat flour

References: Abo-Dief (2020) 
Tempering at $32 \mathrm{C}^{\circ}$

$12 \mathrm{hr}$
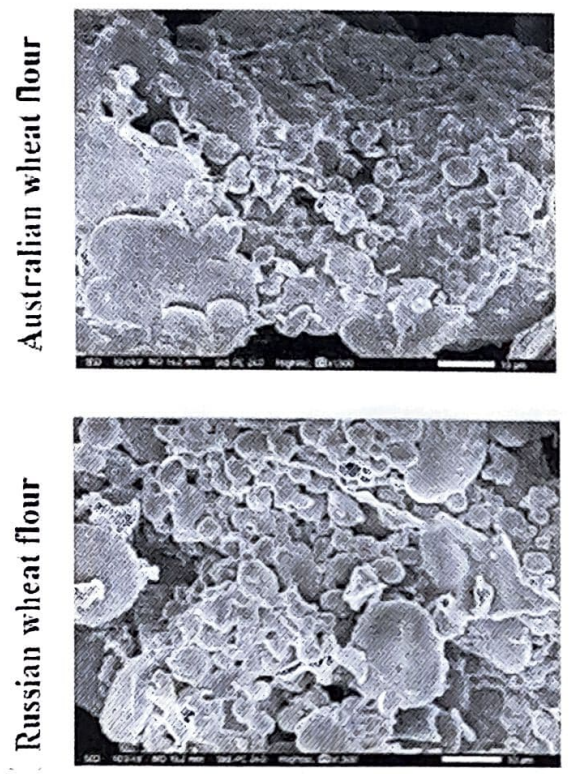

Tempering at $12 \mathrm{C}^{\circ}$

$12 \mathrm{hr}$
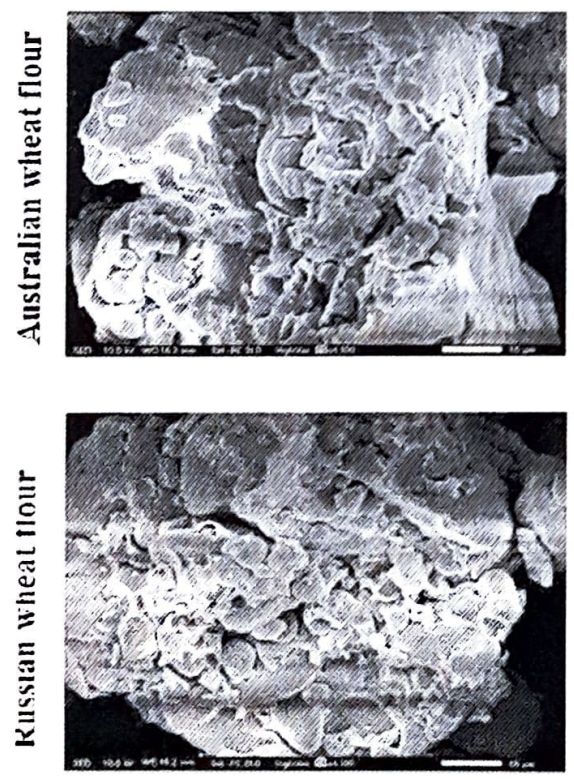

Tempering time

$24 \mathrm{hr}$
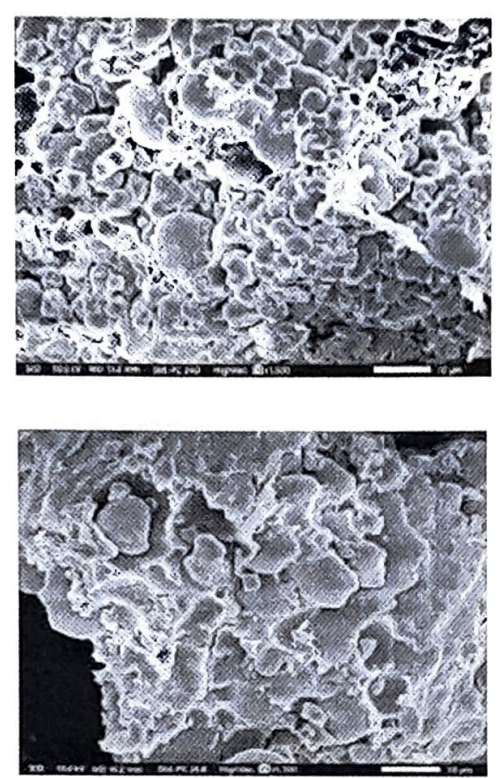

Tempering time

$24 \mathrm{hr}$
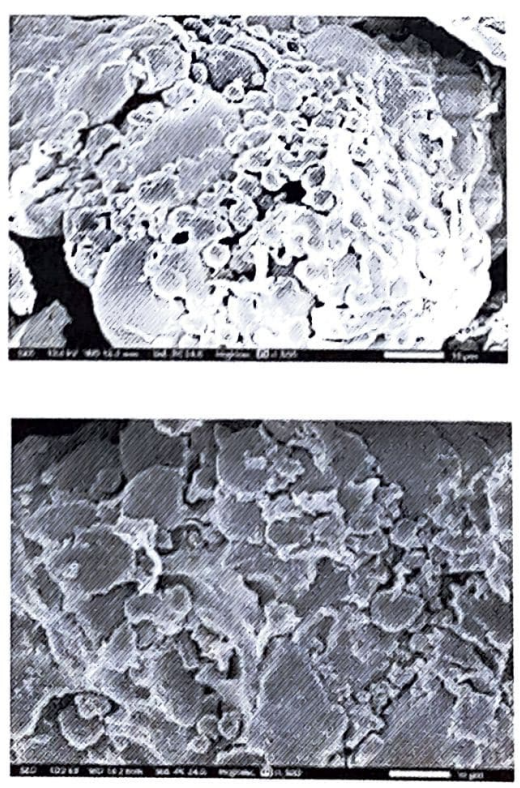

36 hr
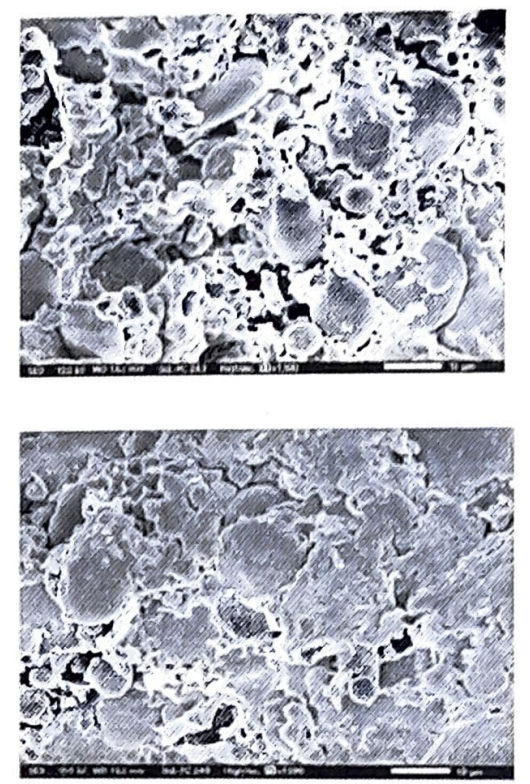

$36 \mathrm{hr}$
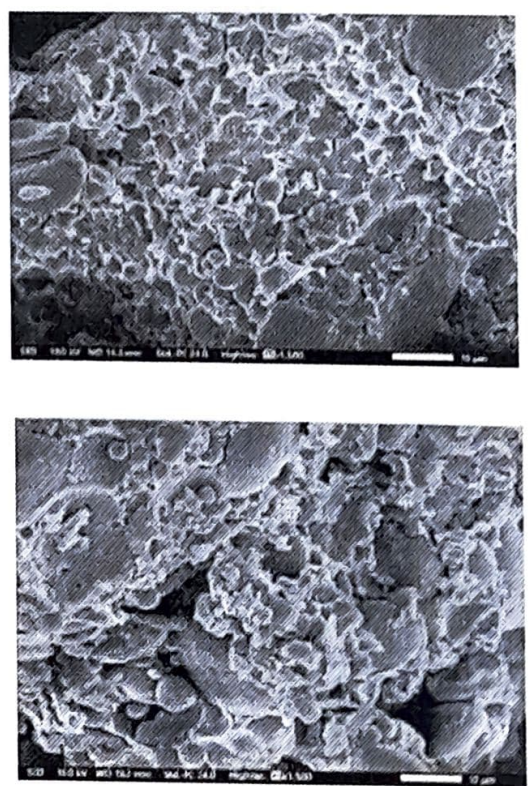

Fig. 2: Effect of tempering conditions and normal milling system on starch appearance for Australian and Russian wheat flour

References: Abo-Dief (2020) 
Ahmad, N., \& Rajab. A. 2018. Textural and cooking qualities of dry Laksa noodle made from semi-wet and wet MR253 flours. Cereal Chemistry, 95: 872-880.

Barak,S.,Mudgil.D.\& Khatkar,B,S. 2014. Effect of flour particle size and damaged starch on the quality of cookies. Journal of Food Science and Technology, 51: 1342-1348.

Barrera, G. N., Bustos, M. C.. Iturriaga, L., Flores, S. K., León, A. E., \& Ribotta, P. D. 2013. Effect of damaged starch on the theological properties of wheat starch suspensions. Journal of Food Engineering, 116: 233-239.

Dhital, S., Shrestha, A. K., \& Gidley, M. J. 2010. Effect of cryo-milling on starches: Functionality and digestibility. Food Hydrocolloids, 24: 152-163.

Hackenberg, S., Verheyen, C., Jekle, M., \& Becker; T. 2016. Effect of mechanically modified wheat flour on dough fermentation properties and bread quality. European Food Research and Technology, 243: 287-296.

Leon,A.E.,Barrera,G. N., Perez, G. T., Ribotta, P. D., \& Rosell, C, M. 2006. Effect of damaged starch levels on flour thermal behaviour and bread staling. European Food Research and Technology, 224:187-192.

Liu, C.. Hong, J., \& Zheng, X. 2017. Effect of heatmoisture treatment on morphological, structural and functional characteristics of ball milled wheat starches. Starch - Stärke, 69: 1-9.

Liu, R., Sun, W., Zhang, Y., Huang, Z., Hu, H., Zhao, M., \& Li, W. 2019. Development of a novel model dough based on mechanically activated cassava starch and gluten protein: Application in bread. Food Chemistry, 300: 196-201

Liu, X., Li, E., Jiang, Y., \& Tian, Y. 2018. Milling Process of Starch. 155-174.

Makowska, A., Szwengiel, A., Kubiak, P., \& Tomaszewska-Gras, J. 2014. Characteristics and structure of starch isolated from triticale. Starch - Stärke, 66: 895-902.

Mancebo, C. M., Picón, J., \& Gómez, M. 2015. Effect of flour properties on the quality characteristics of gluten free sugar-snap cookies. LWT - Food Science and Technology, 64: 264-269.

Ooms, N., Vandromme, E., Brijs, K. \& Delcour,
J.A. 2018. Intact and damaged wheat starch and amylase functionality during multilayered fermented pastry making. Journal of Food Science, 83: 2489-2499.

Posner, E. S..\& Hibbs. A. N. 2005. Wheat flour milling (2nd ed.). St. Paul, MN: AACC International, USA.

Rahil, A., Ali, R., Khan, M. S., Moin, M., \& Kazmi, S. 1. 2015. Comparative study on the physicochemical and rheological parameters of soft wheat flour obtained from three countries. American Journal of Food Science and Nutrition Research, 2: 89-93.

Sakhare, S. D., Inandar, A. A., Gaikwad, S. B., D, I., \& G, V. R. 2014. Roller milling fractionation of green gram (Vigna radiata): optimization of milling conditions and chemical characterization of millstreams. Journal of Food Science and Technology, 51: 3854-3861.

Sakhare,S.D.,Inamdar,A.A.,Indrani,D.,Kiran,M,H ,M.,\& Rao,G.V. 2015. Physicochemical and microstructure analysis of flour mill streams and milled products. Journal of Food Science and Technology, 52,407-414.

Scanlon, M.G., Dexter, J. E., \& Biliaderis,C.G.1988. Particle size related physical properties of flour produced by smooth roll reduction of hard red spring wheat farina. Cereal Chemistry, 65: 486-492.

Shi, L., Li, W., Sun, J., Qiu, Y., Wei, X., Luan, G., Tatsumi, E. 2016. Grinding of maize: The effects of fine grinding on compositional, functional and physicochemical properties of maize flour. Journal of Cereal Science, 68: 25-30.

Suki, F. M. M., Azura, A. R., \& Azahari, B. 2016. Effect of ball milled and ultrasonic sago starch dispersion on sago starch filled natural rubber latex (SSNRL) films. Procedia Chemistry, 19: 782-787.

Tan, X., Zhang, B., Chen, L., Li, X., Li, L., \& Xie, F. 2015. Effect of planetary ball-milling on multi-scale structures and pasting properties of waxy and high-amylose cornstarches. Innovative Food Science \& Emerging Technologies, 30: 198-207.

Vouris, D. G., Lazaridou, A., Mandala, I. G., \& Biliaderis, C. G. 2018. Wheat bread quality attributes using jet milling flour fractions. LWT Food Science and Technology, 92: 540-547. 
Wang, S., Yu, J., Xin, Q., Wang, S., \& Copeland, L. 2017. Effects of starch damage and yeast fermentation on acrylamide formation in bread. Fond Control, 73: 230-236.

Wang,Q., Li, L. \& Zheng,X.2020.A review of milling damaged starch: Generation, measurement. functionality and its effect on starch-based food systems. Food Chemistry, 315: $1-12$.
Wu, F., Li, J., Yang, N., Chen, Y., Jin, Y., \& Xu, $X .2018$. The roles of starch structures in the pasting properties of wheat starch with different degrees of damage. Starch - Stärke, 70: $1-11$.

Zhang, K., Dai, Y.. Hou, H., Li, X., Dong, H., Wang, W., \& Zhang, H. 2019. Influences of grinding on structures and properties of mung bean starch and quality of acetylated starch. Food Chemistry, 294:285-292.

\section{نشا الطحز المحطم في دقيق القمي: التكوين، التركيب، الوظيفة

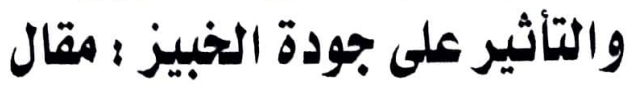$$
\text { محمد فتحي أبوضيف }
$$$$
\text { الشركة العربية للمطاحن والصناعات الغذائية - برج العرب ابوصي }
$$$$
\text { الاسكندرية - جمهورية مصر العربية }
$$

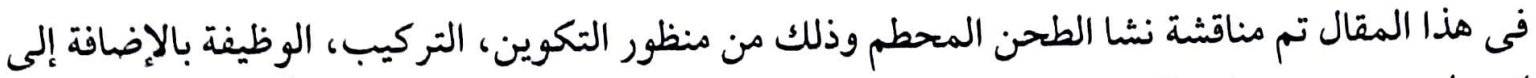

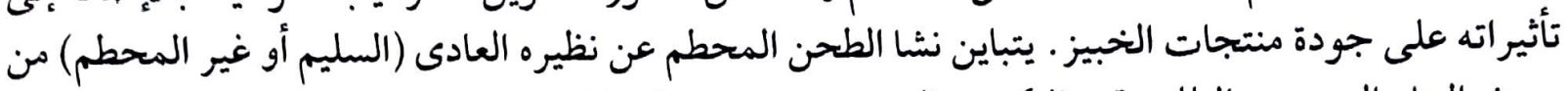

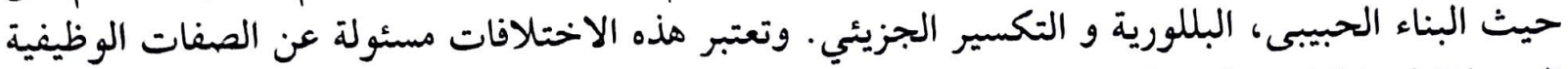

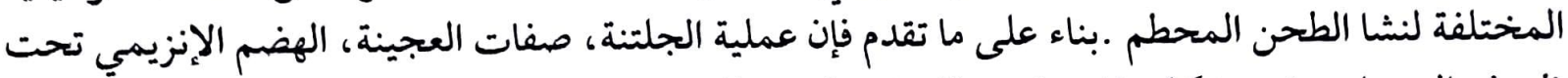

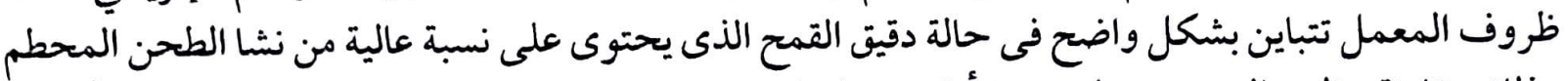

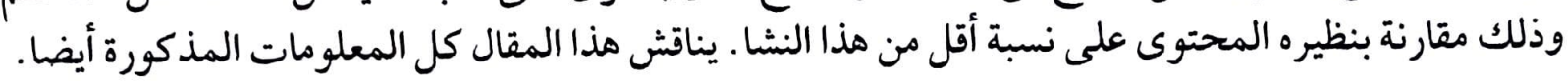

